\title{
Small-incision open distal subpectoral vs. arthroscopic proximal biceps tenodesis for biceps long head tendon lesions with repair of rotator cuff tears
}

\author{
GANG YI $^{1,2^{*}}$, JING YANG $^{3 *}$, LEI ZHANG $^{1,2^{*}}$, YANG LIU $^{1,2 \#}$, XIAOGUANG GUO ${ }^{1,2 \#}$ and SHIJIE FU ${ }^{1,2}$ \\ ${ }^{1}$ Department of Orthopedics; ${ }^{2}$ Academician Workstation in Luzhou; ${ }^{3}$ Department of Obstetrics and Gynecology, \\ Affiliated Traditional Chinese Medicine Hospital of Southwest Medical University, Luzhou, Sichuan 646600, P.R. China
}

Received March 13, 2019; Accepted October 24, 2019

DOI: $10.3892 /$ etm.2019.8284

\begin{abstract}
The curative effect of small-incision open distal subpectoral vs. arthroscopic proximal biceps tenodesis for lesions in the long head of the biceps tendon (LHBT) combined with rotator cuff repairs (RCR) has remained controversial. The aim of the present study was to compare the two surgical methods. A total of 71 patients who received surgical treatment for LHBT lesions accompanied by RC tears were analyzed. Following arthroscopic RCR and tendectomy of the affected LHBT, 35 patients underwent small-incision open distal subpectoral tenodesis through a small incision (the subpectoral group), while the remaining 36 patients received arthroscopic proximal tenodesis (the arthroscopic group). The surgery time and intra-operative blood loss were compared between the two groups. In addition, the clinical outcomes were evaluated using scoring systems for the functional assessment of the shoulder joint. The subpectoral group had a shorter surgery time and less intra-operative blood loss than the arthroscopic group $(\mathrm{P}<0.05)$. The functional scores of the two groups significantly improved as time passed $(\mathrm{P}<0.05)$. The subpectoral group was significantly superior to the arthroscopic group with regard to the American Shoulder and Elbow Surgeons score at 2 weeks post-operatively and visual analog scale score at 2 weeks and 3 months post-operatively $(\mathrm{P}<0.05)$. Small-incision open distal subpectoral and arthroscopic proximal tenodesis were demonstrated to effectively improve the function of the shoulder
\end{abstract}

Correspondence to: Professor Shijie Fu, Department of Orthopedics, Affiliated Traditional Chinese Medicine Hospital of Southwest Medical University, 16 Chun Hui Road, Luzhou, Sichuan 646600, P.R. China

E-mail: fushijieggj@126.com

*Contributed equally as first authors

${ }^{\#}$ Contributed equally as second authors

Key words: tendon, rotator cuff, tenodesis, arthroscopy, pectoralis muscles joint and relieve pain caused by LHBT lesions accompanied by RCR. However, small-incision open distal subpectoral tenodesis had the additional advantage of shorter surgery time, less intra-operative bleeding and encouraging early results compared to arthroscopic proximal tenodesis. The study was registered as a clinical trial in the Chinese Trial Registry (no. ChiCTR1800015643).

\section{Introduction}

Lesions of the long head of the biceps tendon (LHBT) are among the most common causes of shoulder disorders and pain $(1,2)$. LHBT lesions alone are relatively rare; they are mostly associated with other lesions of the shoulder joint, particularly rotator cuff (RC) injury (1,3-8). The normal physiological function of the LHBT depends on the role of the block system, which is mainly composed of supraspinatus (SSP), coracohumeral ligament, superior glenohumeral ligament and subscapularis (SSC) (9). These ligaments are reinforced by the check-points of the SSP and SSC tendons, which maintain LHBT stability in the intertubercular sulcus (Fig. 1). SSP and SSC injuries are more common among RC injuries (10-12), since the tendons in them are used as reinforcement of the block system. SSP and SSC damage leads to instability of the LHBT, easily causing LHBT lesions following RC injury. Studies have indicated that the proportion of LHBT lesions combined with RC injury accounts for 30-69\% $(6,13)$; this was not well known in the past, when only RC injury was treated and the pain caused by LHBT lesions was frequently ignored (14). In recent years, increasing attention has been paid to persistent pain caused by LHBT lesions (15-19). With the development of imaging and arthroscopic technology, it has been recognized that LHBT lesions are caused by repeated friction with the intertubercular sulcus and the surgical method of choice has changed from large-incision to small-incision or minimally invasive treatment under arthroscopy.

In recent years, a large number of comparative studies on the clinical efficacy of LHBT tenotomy and LHBT tenodesis have been performed (20-31), but the results remain controversial. It has been reported that LHBT tenotomy and LHBT tenodesis achieve satisfactory efficacy. As compared with LHBT tenodesis, pure LHBT tenotomy has the advantages 
of simplicity, short surgery time and rapid post-operative recovery $(21,32,33)$, but it may cause complications including Popeye sign deformity $(21,24,25,28)$, upper arm spastic pain, loss of stability of the humeral head (34-36) and reduced forearm supination strength $(20,22,23)$. LHBT tenodesis is a more invasive surgical procedure, but it maintains the length and tension of the original tendon and the strength of the elbow muscle, effectively prevents muscle atrophy and minimizes spastic and Popeye sign deformity in the upper arm $(37,38)$.

Although the clinical manifestations and advantages of LHBT tenodesis in biomechanics have been confirmed, the choice between proximal and distal tenodesis remains controversial. Recent studies have reported frequent residual pain in the intertubercular sulcus following arthroscopic proximal LHBT tenodesis $(39,40)$. In addition, LHBT lesions are frequently combined with other injuries and there are few comparative studies on the clinical treatment of LHBT lesions accompanied by RC repair (RCR). In the present study, the efficacy between small-incision open distal subpectoral tenodesis and arthroscopic proximal tenodesis was analyzed in patients with LHBT lesions accompanied by RCR, with the aim of providing evidence and support for their use in the clinic.

\section{Materials and methods}

Patients and ethics. All clinical procedures were approved by the Ethical Committee of the Affiliated Traditional Chinese Medicine Hospital of Southwest Medical University (Luzhou, China; approval no. KY20180603), performed in accordance with the 1964 Declaration of Helsinki and its later amendments and the study was registered as a clinical trial in the Chinese Trial Registry (no. ChiCTR1800015643). All patients understood the intervention procedure and signed the relevant informed consent form. From June 2014 to June 2016, 71 patients with LHBT lesions with RCR who underwent shoulder arthroscopy met the inclusion criteria for the study. All RC injuries were repaired by arthroscopy and tenodesis was performed after LHBT lesions were cut off under arthroscopy (Fig. 2). Of the 71 patients, 35 were treated with small-incision open distal subpectoral biceps tenodesis (subpectoral group; 17 males and 18 females aged 46-69 years). Arthroscopic proximal biceps tenodesis was performed in 36 patients (arthroscopic group; 16 males and 20 females aged $42-71$ years). All patients were further diagnosed with LHBT lesions combined with RCR by pre-operative medical history, clinical examination, MRI examination and intra-operative microscopy. No statistically significant differences were observed in terms of sex, diabetes, age, smoking, time of onset, type of LHBT lesions (41) or size of $\mathrm{RC}$ tear between the two groups $(\mathrm{P}>0.05$; Table I).

Pre-operative physical examination of the patients clearly indicated that the diseased shoulder was accompanied by limited movement, RC injury and positive signs of LHBT lesions, as determined by tests including the pain arc test (+), Hawkins sign (+), Yergason test (+) and Speed test (+). Imaging examination confirmed that the patients had typical RC injury and LHBT lesions.

Inclusion criteria. The inclusion criteria were as follows: i) Shoulder pain accompanied by limited movement, particularly in terms of functions such as outspreading

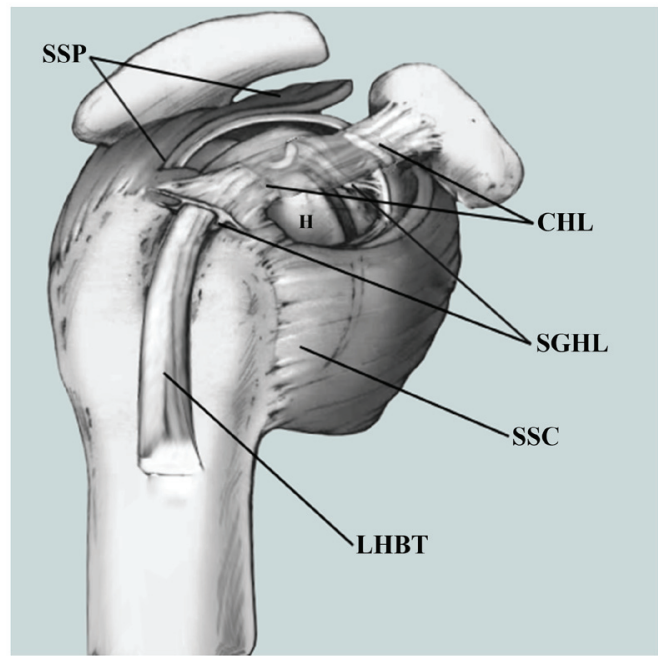

Figure 1. Diagrammatic sketch of the location of LHBT lesions and peripheral ligaments. H, humerus; LHBT, long head of the biceps tendon; SSP, supraspinatus; CHL, coracohumeral ligament; SGHL, superior glenohumeral ligament; SSC, subscapularis.

and anteflexion; ii) shoulder MRI revealed RC injury and abnormal LHBT signal; iii) further arthroscopic confirmation of patients with LHBT lesions accompanied by RC; iv) patients fully understood the surgical method and signed the relevant doctor-patient communication and informed consent forms; v) follow-up time was $>1$ year.

Exclusion criteria. The exclusion criteria were as follows: i) No RC injury or irreparable RC injury; ii) open injury or other serious shoulder joint disease; iii) revision surgery; iv) patients unsuitable for surgery due to chronic wasting disease or infectious diseases; v) patients refused to sign relevant doctor-patient communication or informed consent form; vi) the follow-up time was $<1$ year.

Surgical procedure. The patient was maintained in a recumbent position on the healthy side, with a fixed head and neck and suspended upper limb of the affected side using SPIDER MAN (MAQUET GmbH; able to rotate multi-directionally, effect of free fixation), instead of human traction fixation. The limb was outspread $40^{\circ}$ and anteflexed $15^{\circ}$, the arthroscopic equipment was connected, the skin was disinfected using iodine and alcohol and the sterile towels and waterproof sheet spread were applied (Fig. 3). A $30^{\circ}$ arthroscopy lens was placed in the acromion posterolateral edge, and a planning and a radio frequency instrument was placed in the acromion-anterolateral border. First, the glenohumeral joint was explored and other lesions were detected. The synovial tissue around the tendon in the articular cavity was cleaned by the electric knife using the anterior approach and the hyperplasia osteophytes were properly removed using a drill. A radio frequency ion knife was used to repair the tear edge of the RC in different ways, depending on the type of RC injury. Following the surgery, the LHBT lesions were cut off under arthroscopy, after checking that the fixation was firm (Fig. 4A).

In the subpectoral group, an incision was made $\sim 3 \mathrm{~cm}$ along the inferior margin of the medial ectopectoralis. The skin was incised, the superficial fascia was separated until reaching the 


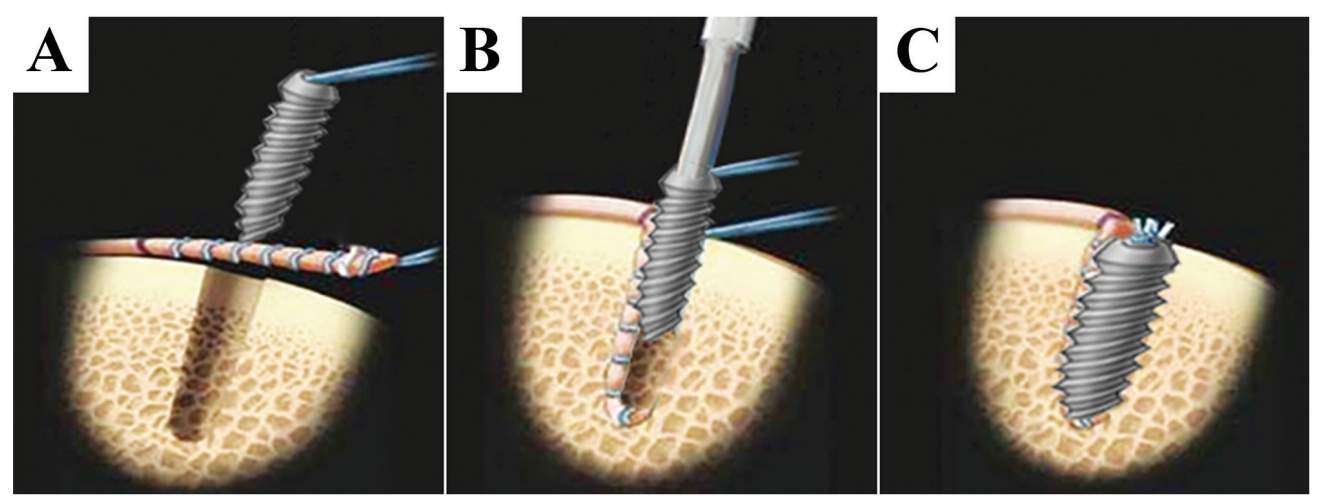

Figure 2. Diagrammatic sketch of biceps tenodesis following tendectomy of the affected LHBT. (A) Removal of LHBT lesions following tendectomy of the affected LHBT, knitting and suturing of the LHBT with tendon suture line, slight polishing of the bony cortex with a grinding drill and drilling at a proper depth with a bone drill. (B) Placement of the knitted LHBT into the drilled tunnel. (C) Tightening of the interference screw. LHBT, long head of the biceps tendon.

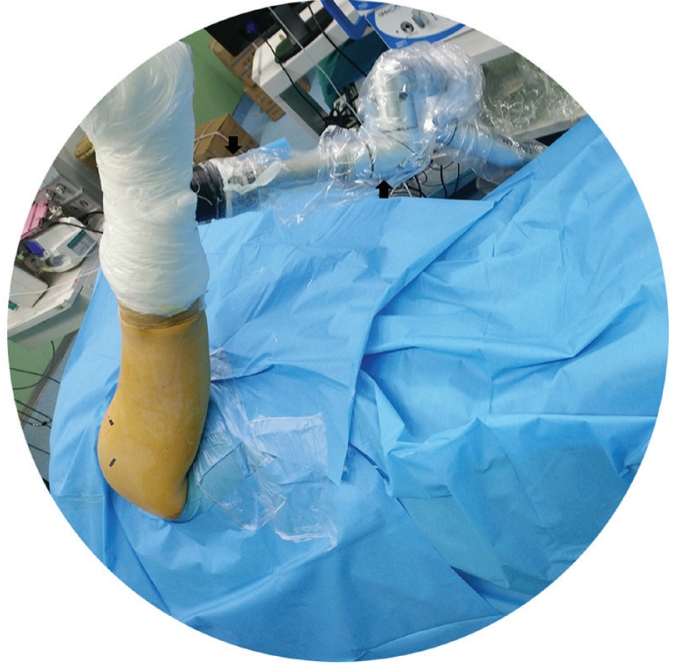

Figure 3. Representative example of surgical position of patients. The patients were maintained in a recumbent position on the healthy side, with a fixed head and neck, suspended upper limb of the affected side with SPIDER MAN, and outspread $\left(40^{\circ}\right)$ and anteflexed $\left(15^{\circ}\right)$ limb.

LHBT, the LHBT was removed under the ectopectoralis, the bony cortex of the ectopectoralis was slightly polished with a grinding drill, a bone drill was used to drill to a proper depth and fixation was performed using a tendon suture (Johnson \& Johnson Medical Equipment Co., Ltd.) and interference screw (MILAGRO ${ }^{\circledR}$; Johnson \& Johnson; Fig. 4B and C). A schematic illustration of small-incision open distal subpectoral tenodesis is provided in Fig. 4D and E. Following re-examination of the supraspinatus, deltoid, LHBT, infraspinatus and teres minor muscles, it was confirmed that there was no obvious active bleeding and a plasma drainage tube was inserted. The incision was stitched layer by layer and compressed using sterile dressing, and the affected limb was bandaged. Following the surgery, the affected limb was suspended or fixed with external braces immediately.

In the arthroscopic tenodesis group, following the confirmation of intra-articular LHBT injury (Fig. 5A), the arthroscope was repositioned to the subacromial space and the tendon sheath of the LHBT was cleared with an electric knife to fully expose the LHBT. The inner part of the sheath was explored. The bony cortex was slightly polished with a polishing head on the intertubercular sulcus, fixed with sutures anchors after stabilizing the proximal LHBT (ThRevo, CF6160H; $5.0 \mathrm{~mm}$, outside diameter x $18.0 \mathrm{~mm}$ length, w/Three\#2 Hi-Fi Suture; Smith \& Nephew plc) (Fig. 5B and C). A schematic illustration of arthroscopic proximal tenodesis is provided in Fig. 5D and E. No obvious active bleeding was observed and a plasma drainage tube was inserted. The incision was stitched layer by layer, compressed using sterile dressing and the affected limb was bandaged. Following the surgery, the affected limb was suspended or fixed with external braces immediately.

Post-operative treatment. The affected shoulder was fixed with external braces immediately after surgery. Routine anti-infection, detumescence, pain relief and intermittent ice compresses were administered and the plasma drainage tube was removed $24 \mathrm{~h}$ post-operatively. At 2 weeks post-operatively, active or passive fist clenching and bending of the elbow, as well as assisted forward bending, back stretching and abduction (Abd) of the affected shoulder flexion were performed. At 3 weeks post-operatively, active forward bending, back stretching and Abd of the affected shoulder were gradually performed. At 6 weeks post-operatively, full-range exercises of the affected shoulder were initiated. Muscle strength training began 3 months later and the patient gradually returned to their original activity level at $\sim 6$ months post-operatively.

Clinical evaluation indicators. The surgery time and intra-operative bleeding volume were recorded. Furthermore, muscle strength, Shoulder joint function, pain and range of motion (ROM) of the shoulder joint were recorded in detail pre-operatively and post-operatively at 2 weeks, 3 months and a final follow-up (the mean follow-up duration was 21 months). Patient satisfaction (16) at $\sim$ one year post-surgery was also evaluated. The shoulder joint function was assessed using the University of California at Los Angeles (UCLA), Constant and American Shoulder and Elbow Surgeons (ASES) scores. The visual analog scale (VAS) score $(15,16)$ was used to evaluate post-operative pain. At the time of the last follow-up, complications were evaluated using ultrasound and biceps apex distance (BAD).

Statistical analysis. Pearson's $\chi^{2}$ test was used to analyze the categorical outcomes. One-way analysis of variance and the paired t-test were used to compare potential differences 
Table I. Comparison of demographic characteristics of patients in the subpectoral tenodesis group and the arthroscopic tenodesis group.

\begin{tabular}{|c|c|c|c|}
\hline Characteristic & Subpectoral group $(\mathrm{n}=35)$ & Arthroscopic group $(\mathrm{n}=36)$ & P-value \\
\hline Age (years) & $53.46 \pm 8.45$ & $54.32 \pm 10.73$ & 0.709 \\
\hline Sex & & & 0.727 \\
\hline Male & 17 & 16 & \\
\hline Female & 18 & 20 & \\
\hline Dominant shoulder & $29(82.9)$ & $31(86.1)$ & 0.705 \\
\hline $\operatorname{BMI}\left(\mathrm{kg} / \mathrm{m}^{2}\right)$ & $24.65 \pm 3.78$ & $23.79 \pm 4.36$ & 0.378 \\
\hline Pain duration (days) & $129.76 \pm 18.36$ & $137.53 \pm 17.78$ & 0.119 \\
\hline Rotator cuff tear size & & & 0.832 \\
\hline Small & 18 & 20 & \\
\hline Medium & 13 & 11 & \\
\hline Large & 4 & 5 & \\
\hline Type of LHBT lesion & & & 0.755 \\
\hline Tendinitis & 24 & 27 & \\
\hline Subluxation & 2 & 1 & \\
\hline Total dislocation & - & - & \\
\hline Partial tear & 9 & 8 & \\
\hline Complete rupture & - & - & \\
\hline Diabetes mellitus & $5(14.3)$ & $3(8.3)$ & 0.676 \\
\hline Smoking & $10(28.6)$ & $12(33.3)$ & 0.664 \\
\hline
\end{tabular}

Continuous data are expressed as the mean \pm standard deviation and constant data are expressed as n (\%). BMI, body mass index.

in the surgery time, intra-operative blood loss and ROM, as well as the UCLA, Constant, ASES and VAS scores between the two groups. Values are expressed as the mean \pm standard deviation. All data were processed using SPSS statistical software (version 20; IBM Corp.). $\mathrm{P}<0.05$ was considered to indicate a statistically significant difference.

\section{Results}

Post-operative conditions. All 71 patients successfully completed the surgery without any serious complications, e.g. vascular or nerve injury. The intra-operative data of the two groups are provided in Table II. The surgery time in the subpectoral group was significantly shorter than that in the arthroscopic group $(\mathrm{P}<0.05)$. Intra-operative blood loss in the subpectoral group was significantly less than that in the arthroscopic group $(\mathrm{P}<0.05)$. The plasma drainage tube was removed $24 \mathrm{~h}$ post-operatively and all incisions achieved grade A healing. The patients were discharged smoothly and no post-operative infection occurred.

Clinical outcomes. The patients were followed up for a minimum of 1.5 years. The mean follow-up duration in the subpectoral group was $21.03 \pm 2.42$ months and that in the arthroscopic group was $21.45 \pm 1.24$ months. The follow-up data of the two groups are provided in Table III. With the prolongation of the follow-up time, the UCLA, Constant and ASES scores increased significantly in each group, while the VAS score decreased significantly; significant differences were observed within the same group at different time-points $(\mathrm{P}<0.05)$. No significant difference was observed in the UCLA, Constant, ASES and VAS scores at the pre-operative stage between the two groups ( $P>0.05)$. Furthermore, no significant difference was observed in the Constant and UCLA scores at 2 weeks post-operatively between the two groups ( $P>0.05)$; however, the ASES score of the subpectoral group at this time-point was significantly higher than that of the arthroscopic group and the VAS score of the subpectoral group was significantly lower than that of the arthroscopic group $(\mathrm{P}<0.05)$. At 3 months post-operatively, there was no significant difference in the UCLA, Constant and ASES scores between the two groups $(\mathrm{P}>0.05)$; however, the VAS score of the subpectoral group at this time-point was still significantly better than that of the arthroscopic group $(\mathrm{P}<0.05)$. No significant difference was observed in the UCLA, Constant, VAS and ASES scores between the two groups at the time-point of final follow-up $(\mathrm{P}>0.05)$.

ROM. The pre-operative ROM of the shoulder joint are described in Table IV and mainly include Abd, internal rotation (IR), external rotation to the side (ERs) and forward flexion (FF). In the subpectoral group, the active FF changed from $138.25 \pm 24.18$ pre-operatively to $160.24 \pm 13.94$ at the time of the final follow-up; furthermore, ERs changed from $45.96 \pm 11.32$ to $59.96 \pm 10.85$, IR from $38.42 \pm 9.18$ to $56.71 \pm 8.73$ and Abd from $145.80 \pm 21.42$ to $170.17 \pm 8.32$. In the arthroscopic tenodesis group, the active FF changed from $136.82 \pm 25.77$ pre-operatively to $157.63 \pm 15.81$ at the final follow-up; furthermore, ERs changed from $46.83 \pm 14.74$ to $58.32 \pm 11.41$, IR from $38.93 \pm 8.35$ to $54.26 \pm 9.45$ and Abd from $148.48 \pm 23.04$ to $168.53 \pm 7.98$ 
Table II. Peri-operative data and comparison between two groups of patients.

\begin{tabular}{lccc}
\hline Item & Subpectoral group $(\mathrm{n}=35)$ & Arthroscopic group $(\mathrm{n}=36)$ & P-value \\
\hline Operative time (min) & $105.90 \pm 15.75$ & $124.38 \pm 18.84$ & $<0.001$ \\
Intra-operative blood loss $(\mathrm{ml})$ & $40.28 \pm 4.92$ & $64.46 \pm 8.77$ & $<0.001$ \\
\hline
\end{tabular}

Values are expressed as the mean \pm standard deviation.

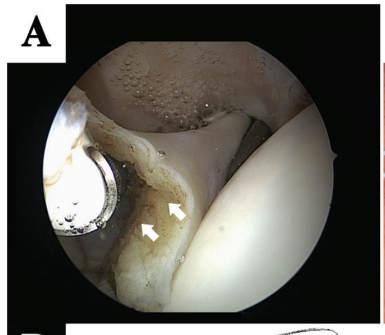

D

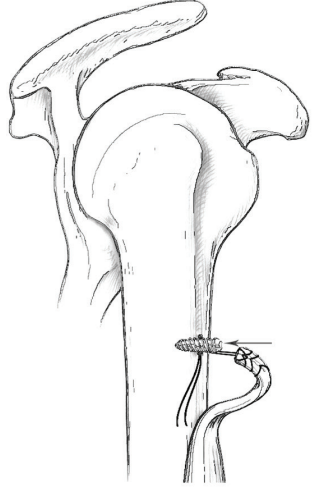

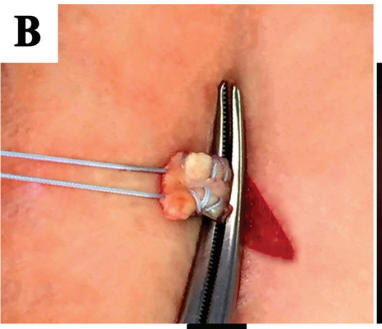

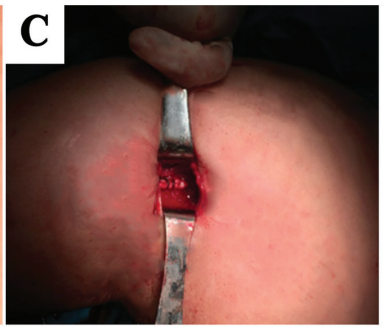

$\mathbf{E}$

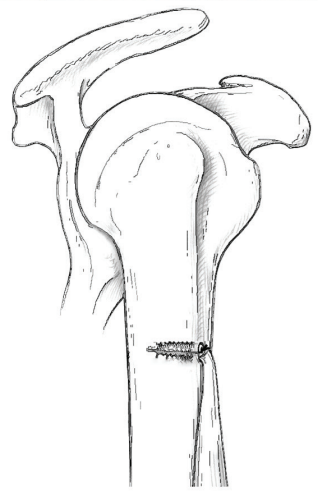

Figure 4. Small-incision open distal subpectoral tenodesis. Arthroscopy images were taken of the surgical procedure. (A) The LHBT was cut off under arthroscopy, the white arrows show the point at which the LHBT was cut. (B) Removal of LHBT under ectopectoralis, knitting and suturing of the LHBT with a tendon suture line. (C) Enhanced fixation of LHBT with interference screw. Schematic illustration of small-incision open distal subpectoral tenodesis, (D) placement of the knitted LHBT into the drilled tunnel and (E) tightening of the interference screw. LHBT, long head of the biceps tendon.

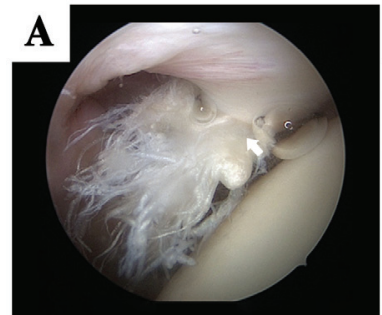

D

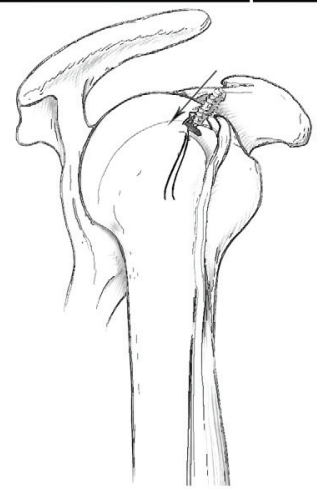

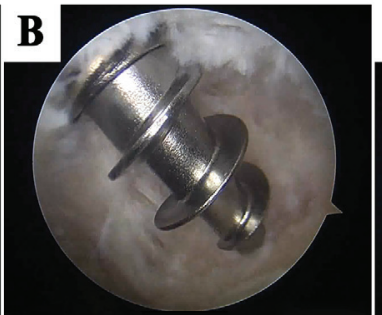

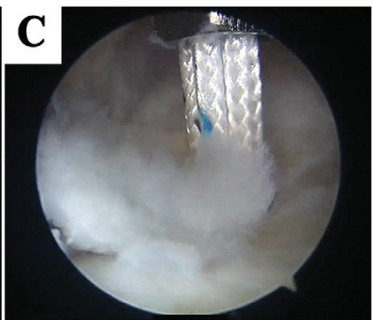

$\mathbf{E}$

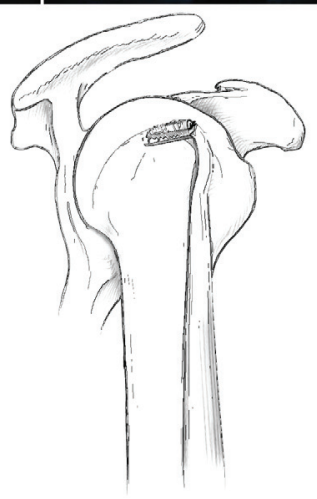

Figure 5. Arthroscopic proximal tenodesis. Arthroscopy images were of the surgical procedure. (A) The white arrows point at the LHBT lesions. (B) The suture anchor was implanted. (C) The LHBT was tied and fixed by suture anchor. Schematic illustration of arthroscopic proximal biceps tenodesis, (D) placement of the knitted LHBT into the drilled tunnel and (E) the LHBT was fixed after the suture anchor was implanted. LHBT, long head of the biceps tendon. 
Table III. Comparison of clinical results between the two groups.

\begin{tabular}{|c|c|c|c|}
\hline Characteristic & Subpectoral group $(n=35)$ & Arthroscopic group $(n=36)$ & P-value \\
\hline \multicolumn{4}{|l|}{ UCLA score } \\
\hline $\mathrm{BL}$ & $18.45 \pm 3.22$ & $18.62 \pm 2.76$ & 0.812 \\
\hline \multicolumn{4}{|c|}{ Post-operative week 2} \\
\hline Score & $25.78 \pm 2.44$ & $24.38 \pm 4.03$ & 0.082 \\
\hline P-value & $<0.001$ & $<0.001$ & \\
\hline \multicolumn{4}{|c|}{ Post-operative month 3} \\
\hline Score & $29.46 \pm 3.71$ & $29.07 \pm 3.15$ & 0.634 \\
\hline P-value & $<0.001$ & $<0.001$ & \\
\hline \multicolumn{4}{|l|}{ Last follow-up } \\
\hline Score & $33.54 \pm 1.07$ & $33.41 \pm 1.24$ & 0.638 \\
\hline P-value & $<0.001$ & $<0.001$ & \\
\hline \multicolumn{4}{|l|}{ Constant score } \\
\hline BL & $51.58 \pm 9.72$ & $49.12 \pm 7.53$ & 0.237 \\
\hline \multicolumn{4}{|c|}{ Post-operative week 2} \\
\hline Score & $59.47 \pm 7.38$ & $58.66 \pm 8.49$ & 0.670 \\
\hline P-value & $<0.001$ & $<0.001$ & \\
\hline \multicolumn{4}{|c|}{ Post-operative month 3} \\
\hline Score & $72.32 \pm 10.71$ & $74.71 \pm 8.04$ & 0.290 \\
\hline P-value & $<0.001$ & $<0.001$ & \\
\hline \multicolumn{4}{|l|}{ Last follow-up } \\
\hline Score & $88.49 \pm 4.55$ & $89.14 \pm 5.37$ & 0.584 \\
\hline P-value & $<0.001$ & $<0.001$ & \\
\hline \multicolumn{4}{|l|}{ ASES score } \\
\hline BL & $42.81 \pm 4.68$ & $41.74 \pm 5.27$ & 0.369 \\
\hline \multicolumn{4}{|c|}{ Post-operative week 2} \\
\hline Score & $58.42 \pm 4.33$ & $53.02 \pm 6.82$ & $<0.001$ \\
\hline P-value & $<0.001$ & $<0.001$ & \\
\hline \multicolumn{4}{|c|}{ Post-operative month 3} \\
\hline Score & $69.83 \pm 6.84$ & $68.43 \pm 6.49$ & 0.379 \\
\hline P-value & $<0.001$ & $<0.001$ & \\
\hline \multicolumn{4}{|l|}{ Last follow-up } \\
\hline Score & $86.13 \pm 7.58$ & $87.69 \pm 5.27$ & 0.316 \\
\hline P-value & $<0.001$ & $<0.001$ & \\
\hline \multicolumn{4}{|l|}{ VAS score } \\
\hline $\mathrm{BL}$ & $7.62 \pm 0.72$ & $7.54 \pm 0.95$ & 0.691 \\
\hline \multicolumn{4}{|c|}{ Post-operative week 2} \\
\hline Score & $4.37 \pm 1.47$ & $5.92 \pm 1.99$ & $<0.001$ \\
\hline P-value & $<0.001$ & $<0.001$ & \\
\hline \multicolumn{4}{|c|}{ Post-operative month 3} \\
\hline Score & $3.25 \pm 0.52$ & $3.68 \pm 0.78$ & 0.008 \\
\hline P-value & $<0.001$ & $<0.001$ & \\
\hline \multicolumn{4}{|l|}{ Last follow-up } \\
\hline Score & $2.04 \pm 0.83$ & $2.13 \pm 0.91$ & 0.665 \\
\hline P-value & $<0.001$ & $<0.001$ & \\
\hline
\end{tabular}

Values are expressed as the mean \pm standard deviation. Within-group P-values pertain to comparison with the BL. BL, baseline; UCLA, University of California Los Angeles constant; ASES, American Shoulder and Elbow Surgeons; VAS, visual analog scale.

(Table IV). All values had improved significantly at the time of the final follow-up $(\mathrm{P}<0.05)$. However, no significant difference was observed between the two groups with regard to improvement in Abd, IR, ERs and FF of the shoulder joint.
Evaluation of complications using BAD and ultrasound. Between the two groups, a significant difference was observed in the synovitis around the bicipital groove at 3 months $(\mathrm{P}<0.05)$, although no significant differences were observed 
Table IV. Comparison of range of motion between the two groups.

\begin{tabular}{|c|c|c|c|}
\hline Item & Subpectoral group $(n=35)$ & Arthroscopic group $(n=36)$ & $\mathrm{P}$-value \\
\hline \multicolumn{4}{|l|}{ BL } \\
\hline $\mathrm{FF}$ & $138.25 \pm 24.18$ & $136.82 \pm 25.77$ & 0.810 \\
\hline $\mathrm{ER}_{\mathrm{S}}$ & $45.96 \pm 11.32$ & $46.83 \pm 14.74$ & 0.782 \\
\hline IR & $38.42 \pm 9.18$ & $38.93 \pm 8.35$ & 0.807 \\
\hline Abd & $145.80 \pm 21.42$ & $148.48 \pm 23.04$ & 0.614 \\
\hline \multicolumn{4}{|c|}{ Last follow-up } \\
\hline FF & $160.24 \pm 13.94$ & $157.63 \pm 15.81$ & 0.464 \\
\hline P-value & $<0.001$ & $<0.001$ & \\
\hline $\mathrm{ER}_{\mathrm{S}}$ & $59.96 \pm 10.85$ & $58.32 \pm 11.41$ & 0.537 \\
\hline P-value & $<0.001$ & $<0.001$ & \\
\hline IR & $56.71 \pm 8.73$ & $54.26 \pm 9.45$ & 0.261 \\
\hline P-value & $<0.001$ & $<0.001$ & \\
\hline Abd & $170.17 \pm 8.32$ & $168.53 \pm 7.98$ & 0.397 \\
\hline P-value & $<0.001$ & $<0.001$ & \\
\hline
\end{tabular}

Values are expressed as the mean \pm standard deviation. Within-group P-values pertain to comparison with the BL. BL, baseline; n.s., no significance $(\mathrm{P}>0.05)$; FF, forward flexion; $\mathrm{ER}_{\mathrm{S}}$, external rotation at the side; IR, internal rotation; Abd, abduction.

Table V. Evaluations of the biceps tendon.

\begin{tabular}{|c|c|c|c|}
\hline Item & Subpectoral group $(n=35)$ & Arthroscopic group $(n=36)$ & P-value \\
\hline \multicolumn{4}{|c|}{ Synovitis around the bicipital groove using U/S } \\
\hline Post-operative month 3 & $2(5.71 \%)$ & $12(33.33 \%)$ & 0.003 \\
\hline Last follow-up & $0(0 \%)$ & $3(8.33 \%)$ & 0.248 \\
\hline $\mathrm{BAD}(\mathrm{cm})$ & $0.26 \pm 0.12$ & $0.29 \pm 0.09$ & 0.237 \\
\hline Retear of rotator cuff & $1(2.86 \%)$ & $3(8.33 \%)$ & 0.627 \\
\hline
\end{tabular}

Continuous data were expressed as the mean \pm standard deviation and constant data are expressed as n (\%). Student's t-test and Chi-squared test of independence were used for statistical analysis. BAD, biceps apex distance; U/S, ultrasonography; n.s., no significance (P>0.05).

between the two groups at the time of the final follow-up. At 3 months post-operatively, synovitis around the bicipital groove was detected in 2 cases $(5.7 \%)$ of the subpectoral group, which disappeared at the time of the final follow-up. In the arthroscopic tenodesis group, 12 cases (33.3\%) of synovitis around the bicipital groove and 3 cases $(8.3 \%)$ of residual synovitis were detected at the time of the final follow-up. At 3 months post-operation, synovitis was significantly higher in the arthroscopic tenodesis group $(\mathrm{P}<0.05)$. Until the last follow-up RC re-tear occurred in one case $(2.9 \%)$ of the subpectoral group and 3 cases $(8.3 \%)$ of the arthroscopic tenodesis group (Table V). There was no significant difference in the prevalence of re-tear between the two groups. There was no case of fixation failure in the biceps in the two groups. No significant difference in the BAD was observed between the two groups at the time of the last follow-up.

\section{Discussion}

Proximal LHBT lesions are a common cause of shoulder pain and dysfunction. Pure LHBT lesions are relatively rare; they are frequently accompanied by RC injury (3-6,20-23). At present, the clinical diagnosis of LHBT lesions is challenging and the condition is easily neglected (42). Another challenge for surgeons is the selection of the appropriate treatment following diagnosis $(21,43)$. For cases of mild LHBT lesion, oral non-steroidal anti-inflammatory drugs, immobilization, physiotherapy and other treatments are usually administered at first, but even in slightly serious cases, surgical intervention is required $(37,44)$. Barber et al $(45)$ have reported that a local tear of the tendon of $<25 \%$ is reversible and conservative treatment may be applied. However, when the tear area exceeds $30 \%$ or the lesions are subluxation or degeneration of the LHBT or above type II superior labrum anterior and posterior lesion, local debridement alone may not achieve satisfactory results. This is due to the fact that pain in the shoulder may persist even following RCR (46-48). LHBT tenotomy or tenodesis is commonly performed at the same time as RCR.

In recent years, most researchers have focused on the comparison between the curative effects of LHBT tenotomy and tenodesis. A large number of clinical comparative 
studies and meta-analyses have assessed the treatment of LHBT lesions combined with RCR with tenotomy and tenodesis (20-23,49-53). These studies indicated that the pain and function of the shoulder joint may be significantly improved by the two methods. Zhang et al (21) observed no significant differences in the curative effect, patient satisfaction and rate of complications between the two groups. However, Oh et al (22) and Lee et al (51) suggested that LHBT tenodesis may maintain the supination function of the forearm and significantly reduce the incidence of Popeye sign deformity, as compared with simple LHBT tenotomy. Oh et al (22) also observed that residual pain in the pectoral muscles following LHBT tenotomy is likely to occur. A meta-analysis by Ge et al (49), including 7 studies, suggested that LHBT tenodesis had a higher Constant score and lower incidence of upper arm spastic pain and Popeye sign deformity than simple tenotomy. Shang et al (50) included 10 high-quality studies in their meta-analysis. No significant differences were identified in the function and incidence of upper arm spastic pain between LHBT tenodesis and tenotomy; however, LHBT tenodesis still had a lower incidence of Popeye sign deformity and a higher Constant score. In general, simple LHBT tenotomy should be avoided in physically active young patients with cosmetic requirements.

Although the advantages of LHBT tenodesis regarding biomechanics and clinical efficacy have been confirmed, there is still considerable controversy regarding the choice of fixing position. Arthroscopic proximal fixation and small incision-assisted distal fixation are common. In recent years, there have also been clinical studies on the comparison of the efficacy between distal and proximal fixation of the LHBT $(15,16,54-58)$, all of which suggested that the two methods have a good clinical efficacy, high patient satisfaction and few complications; no significant differences were observed in functional recovery, pain improvement and complications between the two methods. However, in the study by Duchman et al (15), a significant difference was observed in the shoulder flexion function between the two groups. Few studies compared and analyzed the efficacy of the preliminary phase following surgery, and it was therefore not possible to comprehensively evaluate the efficacy. In addition, LHBT lesions alone are rare; they are frequently combined with other complex shoulder diseases, such as subacromial impingement, synovitis of shoulder joint, which was a limitation of the present study. To date, only a small number of studies have compared the clinical efficacy between distal and proximal fixation of the LHBT in the treatment of patients with LHBT lesions accompanied by RCR.

According to the results of the present study, small-incision open distal subpectoral and arthroscopic proximal tenodesis may effectively improve the function of the shoulder joint and relieve pain. Up to the last follow-up, no significant difference in the shoulder activity degree was observed between the two groups. Small-incision open tenodesis had further advantages pertaining to surgery time and amount of inter-operative blood loss. At 2 weeks following surgery, the VAS and ASES scores of the subpectoral group were higher than those of the arthroscopic group. In the treatment of LHBT lesions combined with RCR, the negative responses observed in the arthroscopic group during the early follow-up, as compared with the effect in the subpectoral group, may be due to early intrapectoral inflammation in the arthroscopic group. On the other hand, LHBT tendonitis may have pre-existed. Arthroscopy is the gold standard for diagnosing LHBT lesions (59); even under maximum visualization during shoulder arthroscopy (60), the average moving length of the LHBT in the cadaver model is $15-19 \mathrm{~mm}(61,62)$, which is $\sim 14 \mathrm{~mm}$ in the human body (63). Only $78 \%$ of the length from the beginning of LHBT to the lower edge of the tendon of the subscapularis muscle and $55 \%$ of the proximal edge of the pectoralis major muscle may be observed, which means that nearly $1 / 3$ of the tendinous parts of the LHBT cannot be observed in the joint (62). Moon et al (64) reported that $\sim 80 \%$ of intra-articular tendon tears had hidden lesions extending to the outer part of the distal joint. Therefore, distal tenodesis is considered to be a better option for removing all hidden LHBT lesions, as it is challenging to control the length and tension of the LHBT via arthroscopic proximal tenodesis. On the other hand, the early intrapectoral inflammation in the arthroscopic group may be due to tension-length mismatch or LHBT tenosynovitis caused by the insertion of a fixation screw under the acromion; small-incision open distal subpectoral tenodesis is able to remove all hidden LHBT lesions and avoid pain caused by inflammation of remaining LHBT lesions. In the present study, the identification of synovitis around the bicipital groove was an important result. Therefore, as compared with arthroscopic proximal tenodesis, small-incision open distal subpectoral distal tenodesis is a more effective way to relieve pain and avoid post-operative LHBT tenosynovitis. However, regardless of the surgical method, the present study suggested that the synovitis around the bicipital groove did not completely disappear at 3 months post-operatively. Therefore, in order to obtain better results as rapidly as possible, the inflammatory tissue must be carefully cleaned during surgery.

The present study had certain limitations. First, it was not a randomized controlled trial or a prospective trial. Furthermore, the average follow-up time of $\sim 21$ months employed in the study is insufficient to assess long-term outcomes. In addition, the strength of the elbow joint was not assessed and not all types of RC injury (such as rupture of at least two of the four RC tendons) were covered. Due to the lack of continuous MRI and LHBT biopsy, it was not possible to confirm whether the advantages of small-incision open distal subpectoral biceps tenodesis in early functional therapy and remaining biceps tendinitis were directly correlated, which may be the focus of future research.

In conclusion, small-incision open distal subpectoral and arthroscopic proximal biceps tenodesis may effectively improve the function of the shoulder joint and relieve pain in the treatment of LHBT lesions accompanied by RC tears. By contrast, small-incision open distal subpectoral tenodesis has the advantages of shorter surgery time, less intra-operative bleeding and encouraging early results over arthroscopic proximal tenodesis. However, regardless of the surgical method, special attention should be paid to the careful removal of the inflammatory tissue.

\section{Acknowledgements}

Not applicable. 


\section{Funding}

This work was supported by the Academician Workstation Construction Project of Luzhou, Sichuan Province, China (grant no. 20180101).

\section{Availability of data and materials}

The datasets generated and/or analyzed during the current study are not publicly available due to being restricted by the medical ethics committee of the Affiliated Traditional Chinese Medicine Hospital of Southwest Medical University but are available from the correspoinding author on reasonable request for researchers who meet the criteria to access confidential information.

\section{Authors' contributions}

GY and SF designed the research and wrote the first draft of the manuscript. GY, JY and LZ performed the data acquisition and follow ups of patients. YL and JY analyzed and interpreted the data as well as finalized the manuscript. XG and SF Processed pictures and proofread the manuscript. All authors read and approved the final version of the manuscript.

\section{Ethics approval and consent to participate}

All clinical procedures were approved by the Ethics Committee of the Affiliated Traditional Chinese Medicine Hospital of Southwest Medical University (Luzhou, China; approval no. KY20180603), performed in accordance with the 1964 Declaration of Helsinki and its later amendments and the study was registered as a clinical trial in the Chinese Trial Registry (no. ChiCTR1800015643). All patients understood the intervention procedure and signed the relevant informed consent form.

\section{Patient consent for publication}

Not applicable.

\section{Competing interests}

The authors declare that they have no competing interests.

\section{References}

1. Boileau P, Baqué F, Valerio L, Ahrens P, Chuinard C and Trojani C: Isolated arthroscopic biceps tenotomy or tenodesis improves symptoms in patients with massive irreparable rotator cuff tears. J Bone Joint Surg Am 89: 747-757, 2007.

2. Landreau P, Catteeuw A, Hamie F, Saithna A, Sonnery-Cottet B and Smigielski R: Anatomic study and reanalysis of the nomenclature of the anterolateral complex of the knee focusing on the distal iliotibial band: Identification and description of the condylar strap. Orthop J Sports Med 7: 2325967118818064, 2019.

3. Ataoglu MB, Cetinkaya M, Ozer M, Ayanoglu T and Kanatli U: The high frequency of superior labrum, biceps tendon, and superior rotator cuff pathologies in patients with subscapularis tears: A cohort study. J Orthop Sci 23: 304-309, 2018.

4. Kennedy NI, Sanchez G, Mannava S, Ferrari MB, Frangiamore SJ and Provencher MT: Arthroscopic rotator cuff repair with mini-open subpectoral biceps tenodesis. Arthrosc Tech 6: e1667-e1674, 2017.
5. Su WR, Budoff JE and Lou JP: The effect of posterosuperior rotator cuff tears and biceps loading on glenohumeral translation. Arthroscopy 26: 578-586, 2010.

6. Desai SS and Mata HK: Long head of biceps tendon pathology and results of tenotomy in full-thickness reparable rotator cuff tear. Arthroscopy 33: 1971-1976, 2017.

7. Hassan S and Patel V: Biceps tenodesis versus biceps tenotomy for biceps tendinitis without rotator cuff tears. J Clin Orthop Trauma 10: 248-256, 2019.

8. Forsythe B, Agarwalla A, Puzzitiello RN, Mascarenhas R and Werner BC: Rates and risk factors for revision open and arthroscopic proximal biceps tenodesis. Orthop J Sports Med 7: $2325967118825473,2019$.

9. Godenèche A, Nové-Josserand L, Audebert S, Toussaint B and Denard PJ; French Society for Arthroscopy (SFA) and Lädermann A: Relationship between subscapularis tears and injuries to the biceps pulley. Knee Surg Sports Traumatol Arthrosc 25: 2114-2120, 2017.

10. Lee SH, Nam DJ, Kim SJ and Kim JW: Comparison of clinical and structural outcomes by subscapularis tendon status in massive rotator cuff tear. Am J Sports Med 45: 2555-2562, 2017.

11. Motley GS, Guengerich B, Schuller T and Turbyfill A: The ramp test: An arthroscopic technique for confirming intra-articular subluxation and instability of the long head of the biceps tendon within the shoulder. Arthrosc Tech 7: e327-e330, 2018.

12. Osti L, Buda M, Buono AD, Osti R and Massari L: Clinical evidence in the treatment of rotator cuff tears with hyaluronic acid. Muscles Ligaments Tendons J 5: 270-275, 2016.

13. Shi LL, Mullen MG, Freehill MT, Lin A, Warner JJ and Higgins LD: Accuracy of long head of the biceps subluxation as a predictor for subscapularis tears. Arthroscopy 31: 615-619, 2015.

14. Watson ST, Robbins CB, Bedi A, Carpenter JE, Gagnier JJ and Miller BS: Comparison of outcomes 1 year after rotator cuff repair with and without concomitant biceps surgery. Arthroscopy 33: 1928-1936, 2017.

15. Duchman KR, DeMik DE, Uribe B, Wolf BR and Bollier M: Open versus arthroscopic biceps tenodesis: A comparison of functional outcomes. Iowa Orthop J 36: 79-87, 2016.

16. Green JM, Getelman MH, Snyder SJ and Burns JP: All-Arthroscopic suprapectoral versus open subpectoral tenodesis of the long head of the biceps brachii without the use of interference screws. Arthroscopy 33: 19-25, 2017.

17. Xu GJ and Dai XS: Tenotomy fixed on distal trochlea under arthroscopy for long head of biceps tendon and rotator cuff tear. Zhongguo Gu Shang 31: 612-616, 2018 (In Chinese).

18. Veen EJD, Koorevaar CT and Diercks RL: Using the long head of biceps tendon autograft as an anatomical reconstruction of the rotator cable: An arthroscopic technique for patients with massive rotator cuff tears. Arthrosc Tech 7: e699-e703, 2018.

19. Saithna A, Longo A, Leiter J, Old J and MacDonald PM: Shoulder arthroscopy does not adequately visualize pathology of the long head of biceps tendon. Orthop J Sports Med 4: 2325967115623944, 2016

20. Meraner D, Sternberg C, Vega J, Hahne J, Kleine M and Leuzinger J: Arthroscopic tenodesis versus tenotomy of the long head of biceps tendon in simultaneous rotator cuff repair. Arch Orthop Trauma Surg 136: 101-106, 2016.

21. Zhang Q, Zhou J, Ge H and Cheng B: Tenotomy or tenodesis for long head biceps lesions in shoulders with reparable rotator cuff tears: A prospective randomised trial. Knee Surg Sports Traumatol Arthrosc 23: 464-469, 2015.

22. Oh JH, Lee YH, Kim SH, Park JS, Seo HJ, Kim W and Park HB: Comparison of treatments for superior labrum-biceps complex lesions with concomitant rotator cuff repair: A prospective, randomized, comparative analysis of debridement, biceps tenotomy, and biceps tenodesis. Arthroscopy 32: 958-967, 2016.

23. Franceschi F, Longo UG, Ruzzini L, Rizzello G, Maffulli N and Denaro V: No advantages in repairing a type II superior labrum anterior and posterior (SLAP) lesion when associated with rotator cuff repair in patients over age 50: A randomized controlled trial. Am J Sports Med 36: 247-253, 2008

24. De Carli A, Vadalà A, Zanzotto E, Zampar G, Vetrano M, Iorio R and Ferretti A: Reparable rotator cuff tears with concomitant long-head biceps lesions: Tenotomy or tenotomy/tenodesis? Knee Surg Sports Traumatol Arthrosc 20: 2553-2558, 2012.

25. Koh KH, Ahn JH, Kim SM and Yoo JC: Treatment of biceps tendon lesions in the setting of rotator cuff tears: Prospective cohort study of tenotomy versus tenodesis. The Am J Sports Med 38: 1584-1590, 2010. 
26. Cho NS, Cha SW and Rhee YJ: Funnel tenotomy versus intracuff tenodesis for lesions of the long head of the biceps tendon associated with rotator cuff tears. Am J Sports Med 42: 1161-1168, 2014

27. Karlsson J: In reparable rotator cuff tears with lesions of the long head of the biceps brachii tendon, tenotomy did not differ from tenodesis in terms of function or pain. J Bone Joint Surg Am 99: $351,2017$.

28. Ikemoto RY, Pileggi PE, Murachovsky J, Nascimento LG, Serpone RB, Strose E and Oliveira LH: Tenotomy with or without tenodesis of the long head of the biceps using repair of the rotator cuff. Rev Bras Ortop 47: 736-740, 2015.

29. Kukkonen J, Rantakokko J, Virolainen $P$ and Aärimaa V: The effect of biceps procedure on the outcome of rotator cuff reconstruction. ISRN Orthop 2013: 840965, 2013.

30. Sentürk I, Ozalay M, Akpınar S, Leblebici B, Cınar BM and Tuncay C: Clinical and isokinetic comparison between tenotomy and tenodesis in biceps pathologies. Acta Orthop Traumatol Turc 45: 41-46, 2011.

31. Delle Rose G, Borroni M, Silvestro A, Garofalo R, Conti M, De Nittis P and Castagna A: The long head of biceps as a source of pain in active population: Tenotomy or tenodesis? A comparison of 2 case series with isolated lesions. Musculoskelet Surg 96 (Suppl 1): S47-S52, 2012.

32. Ahmad CS, DiSipio C, Lester J, Gardner TR, Levine WN and Bigliani LU: Factors affecting dropped biceps deformity after tenotomy of the long head of the biceps tendon. Arthroscopy 23: 537-541, 2007.

33. Klinger HM, Spahn G, Baums MH and Steckel H: Arthroscopic debridement of irreparable massive rotator cuff tears-a comparison of debridement alone and combined procedure with biceps tenotomy. Acta Chir Belg 105: 297-301, 2005.

34. Friedman JL, FitzPatrick JL, Rylander LS, Bennett C, Vidal AF and McCarty EC: Biceps tenotomy versus tenodesis in active patients younger than 55 years: Is there a difference in strength and outcomes?. Orthop J Sports Med 3: 2325967115570848, 2015.

35. Gervasi E and Sebastiani E and Cautero E: No-holes transpectoral tenodesis technique tenotomy of the long head of the biceps brachii. Muscles Ligaments Tendons J 6: 427-432, 2016.

36. Park JY, Lee JH, Oh KS, Chung SW, Bang JY and Noh YM: Bridge Tenodesis: A Secure fixation technique for biceps long head tendinopathy during arthroscopic rotator cuff repair using a suture-bridge technique. Arthrosc Tech 5: e1077-e1081, 2016.

37. Nassos JT and Chudik SC: Arthroscopic rotator cuff repair with biceps tendon augmentation. Am J Orthop (Belle Mead NJ) 38: 279-281, 2009

38. Elser F, Braun S, Dewing CB, Giphart JE and Millett PJ: Anatomy, function, injuries, and treatment of the long head of the biceps brachii tendon. Arthroscopy 27: 581-592, 2011.

39. Hufeland M, Kolem C, Ziskoven C, Kircher J, Krauspe R and Patzer T: The influence of suprapectoral arthroscopic biceps tenodesis for isolated biceps lesions on elbow flexion force and clinical outcomes. Knee Surg Sports Traumatol Arthrosc 25 3220-3228, 2017.

40. Faruqui S, Kotob MA and Hanna CC and Foad A: The modified Norwegian method of biceps tenodesis: How well does it work? Knee Surg Sports Traumatol Arthrosc 25: 3264-3269, 2017.

41. Chen $\mathrm{CH}, \mathrm{Hsu} \mathrm{KY}$, Chen WJ and Shih CH: Incidence and severity of biceps long head tendon lesion in patients with complete rotator cuff tears. J Trauma 58: 1189-1193, 2005.

42. Jeong JY, Park SM, Park YE and Yoo JC: Morphological classification of anatomical variants of the intra-articular portion of the long head of the biceps brachii tendon and analysis of the incidence and the relationship with shoulder disease for each subtype. J Orthop Surg (Hong Kong) 25: $2309499017742207,2017$.

43. Ciccotti MG: Editorial commentary: The long head of the biceps brachii tendon-the shoulder surgeon's conundrum. Arthroscopy 33: 1937-1939, 2017.

44. Frost A, Zafar MS and Maffulli N: Tenotomy versus tenodesis in the management of pathologic lesions of the tendon of the long head of the biceps brachii. Am J Sports Med 37: 828-833, 2009.

45. Barber FA, Byrd JW, Wolf EM and Burkhart SS: How would you treat the partially torn biceps tendon. Arthroscopy 17: 636-639, 2001.
46. Kelly AM, Drakos MC, Fealy S, Taylor SA and O'Brien SJ: Arthroscopic release of the long head of the biceps tendon: Functional outcome and clinical results. Am J Sports Med 33: 208-213, 2005.

47. Maynou C, Mehdi N, Cassagnaud X, Audebert S and Mestdagh H: Clinical results of arthroscopic tenotomy of the long head of the biceps brachii in full thickness tears of the rotator cuff without repair: 40 cases. Rev Chir Orthop Réparatrice Appar Mot 91: 300-306, 2005 (In French).

48. Kim YS, Jeong JY and Lee HJ: Arthroscopic tenodesis of the long head of the biceps tendon. JBJS Essent Surg Tech 7: e19, 2017.

49. Ge H, Zhang Q, Sun Y, Li J, Sun L and Cheng B: Tenotomy or tenodesis for the long head of biceps lesions in shoulders: A systematic review and meta-analysis. PLoS One 10: e0121286, 2015.

50. Shang X, Chen J and Chen S: A meta-analysis comparing tenotomy and tenodesis for treating rotator cuff tears combined with long head of the biceps tendon lesions. PLoS One 12: e0185788, 2017.

51. Lee HJ, Jeong JY, Kim CK and Kim YS: Surgical treatment of lesions of the long head of the biceps brachii tendon with rotator cuff tear: A prospective randomized clinical trial comparing the clinical results of tenotomy and tenodesis. J Shoulder Elbow Surg 25: 1107-1114, 2016

52. Leroux T, Chahal J, Wasserstein D, Verma NN and Romeo AA: A systematic review and meta-analysis comparing clinical outcomes after concurrent rotator cuff repair and long head biceps tenodesis or tenotomy. Sports Health 7: 303-307, 2015

53. Hsu AR, Ghodadra NS, Provencher MT, Lewis PB and Bach BR: Biceps tenotomy versus tenodesis: A review of clinical outcomes and biomechanical results. J Shoulder Elbow Surg 20: 326-332, 2011.

54. Yi Y, Lee JM, Kwon SH and Kim JW: Arthroscopic proximal versus open subpectoral biceps tenodesis with arthroscopic repair of small or medium-sized rotator cuff tears. Knee Surg Sports Traumatol Arthrosc 24: 3772-3778, 2016

55. Gombera MM, Kahlenberg CA, Nair R, Saltzman MD and Terry MA: All-arthroscopic suprapectoral versus open subpectoral tenodesis of the long head of the biceps brachii. Am J Sports Med 43: 1077-1083, 2015.

56. Biz C, Vinanti GB, Rossato A, Arnaldi E and Aldegheri R: Prospective study of three surgical procedures for long head biceps tendinopathy associated with rotator cuff tears. Muscles Ligaments Tendons J 2: 133-136, 2012.

57. Werner BC, Lyons ML, Evans CL, Griffin JW, Hart JM, Miller MD and Brockmeier SF: Arthroscopic suprapectoral and open subpectoral biceps tenodesis: A comparison of restoration of length-tension and mechanical strength between techniques. Arthroscopy 31: 620-627, 2015

58. Lutton DM, Gruson KI, Harrison AK, Gladstone JN and Flatow EL: Where to tenodese the biceps: Proximal or distal? Clin Orthop Relat Res 469: 1050-1055, 2011.

59. Bennett WF: Visualization of the anatomy of the rotator interval and bicipital sheath. Arthroscopy 17: 107-111, 2001.

60. Hart ND, Golish SR and Dragoo JL: Effects of arm position on maximizing intraarticular visualization of the biceps tendon: A cadaveric study. Arthroscopy 28: 481-485, 2012.

61. Taylor SA, Khair MM, Gulotta LV, Pearle AD, Baret NJ, Newman AM, Dy CJ and O'Brien SJ: Diagnostic glenohumeral arthroscopy fails to fully evaluate the biceps-labral complex. Arthroscopy 31: 215-224, 2015.

62. Festa A, Allert J, Issa K, Tasto JP and Myer JJ: Visualization of the extra-articular portion of the long head of the biceps tendon during intra-articular shoulder arthroscopy. Arthroscopy 30: 1413-1417, 2014.

63. Gilmer BB, DeMers AM, Guerrero D, Reid JB III, Lubowitz JH and Guttmann D: Arthroscopic versus open comparison of long head of biceps tendon visualization and pathology in patients requiring tenodesis. Arthroscopy 31: 29-34, 2015.

64. Moon SC, Cho NS and Rhee YG: Analysis of 'hidden lesions' of the extra-articular biceps after subpectoral biceps tenodesis: The subpectoral portion as the optimal tenodesis site. Am J Sports Med 43: 63-68, 2015.

This work is licensed under a Creative Commons Attribution-NonCommercial-NoDerivatives 4.0 International (CC BY-NC-ND 4.0) License. 